\title{
BOILING HEAT TRANSFER AND PRESSURE DROP IN SINGLE RECTANGULAR MICROCHANNEL
}

\author{
O. Samoteeva, B. Palm \\ Royal Institute of Technology, Stockholm, Sweden
}

\begin{abstract}
One of the goals of this paper is to investigate the two-phase flow characteristics of the refrigerant changing phase in a high aspect ratio (1:30) rectangular vertically placed microchannel. The hydraulic diameter of the channel is $0,39 \mathrm{~mm}$. The experimental data were collected for the refrigerant R134a for mass fluxes varying from 200 to $970 \mathrm{~kg} / \mathrm{m}^{2} \mathrm{~s}$ and a heat flux range of 0,6-28 $\mathrm{kW} / \mathrm{m}^{2}$. The results of the heat transfer investigation have shown that the heat transfer coefficient is not influenced by the mass flux or vapour quality but only by heat flux, thus indicating the dominance of nucleate boiling or a related mechanism. In comparison to several conventional correlations from the literature, it was shown that the correlations by Lazarek and Black, 1982 predict the heat transfer coefficient best, the data scattering up to 35\%. Measurements have shown that the pressure drop increases approximately linearly with the mass flux.
\end{abstract}

\section{Nomenclature}

$\begin{array}{ll}\mathrm{P} & \text { perimeter } \\ \mathrm{z} & \text { height, vertical location } \\ \mathrm{g} & \text { acceleration due to gravity }\end{array}$

Bo

boiling number

Co

$$
B o=\frac{\dot{q}}{\dot{m} H_{\mathrm{lg}}}
$$

confinement number

$$
C o=\sqrt{\frac{\sigma}{g\left(\rho_{l}-\rho_{g}\right) D^{2}}}
$$

\section{Subscripts}

$\lg$

r

liquid-gas, latent

gr

gravitational

reduced

acc

accelerational

\section{Introduction}

Minimization of the technology and equipment is a trend that nowadays is dominating many research areas. The interest in reducing the size of heat exchangers without diminishing their heat transfer characteristics has aroused based on numerous necessities of our times. One important need that led to the intensification of research in this area is our concern with the state of the environment. The phase-out of hydrofluorocarbons (HFCs) and hydrochlorofluorocarbons (HCFCs) that are considered to increase the concentration of the greenhouse gases in the atmosphere causes the re-birth of the use of natural refrigerants. By natural refrigerants are commonly understood hydrocarbons, ammonia, carbon dioxide and water, all of which are present in large quantities in the environment due to natural processes. Many of the natural refrigerants are flammable and for safety reasons it is important not to have an excessive quantity of them in a system that is used in the 
living area. This can be solved by the use of compact systems with small internal volumes, which will in turn reduce the amount of leakage. Another input into the reduction of the size of heat exchangers has come from the increasing demand from different industries, where the size, weight and volume became of growing importance. This refers to the electronic industry, where cooling of electronics has reached the need for introducing liquid cooling equipment for removing high heat fluxes from concise areas. Automotive industry nowadays demands efficient light-weighted and compact designs of heat exchangers. Possible future applications of the compact heat exchangers working on fluids with of without change of phase are rising from nearly all industries and technologies.

It has been shown by Palm, 2001 that the biggest advantage from the reduction of the diameter can be achieved in the heat exchangers where the fluid is at the single-phase and laminar. There, by a reduction of the inner diameter in half, the heat transfer coefficient doubles, the necessary heat transfer area is reduced to one half and the internal volume would decrease by the factor of four. Other benefits such as reduction of the tube length and wall thickness are also to be mentioned. Pressure drop in this case is kept constant. In turbulent single-phase flow these benefits are smaller, but similar. The analysis of the benefits for two-phase flow is more complicated, as there is a dependence of the heat transfer coefficient on the flow regime, and at the moment general correlations for calculation of the heat transfer and pressure drop do not exist.

The limit of enhancement of the heat transfer coefficient for boiling and condensation in microchannels varies from case to case and is not agreed upon. One of the disagreements between the scientists working with compact devices and particularly heat exchangers is caused by the edge of definition of micro-scale heat exchanger. It is known that generally the classical thermal and fluid dynamics theories are not applicable for micro-scale applications starting at some point of size reduction. This may be explained by the fact that some of the studied phenomena that were not important in the large scale, start dominating the thermal and fluid dynamics characteristics. Therefore some authors refer to the scale where classical theories stop working as micro-scale. However, this threshold is wide and differs from a condition to another, therefore cannot be generally stated once and for all. Another group of authors refer to the scale of micro devices as below $100 \mu \mathrm{m}$. Kandlikar, 2002 is proposing to refer to the channels of 10 to $200 \mu \mathrm{m}$ as micro-, of $200 \mu \mathrm{m}$ to $3 \mathrm{~mm}$ as mini- and above $3 \mathrm{~mm}$ as conventional channels. More conventional definition of the micro scale comes from $1 \mu \mathrm{m}$ size, as a general start of the micro-region. However, in some cases the application of the classical theory may stop working already at $1 \mathrm{~mm}$. It was proposed by Kew and Cornwell, 1997 to use confinement number Co>0,5 as a threshold to the microscale. It also seems appropriate to define the microscale when the bubbles become confined in the flow, as it is when the classical approach stops working.

\section{Theory}

The classical theories developed for conventional size channels are not generally applicable for the mini- and micro-scale. The phenomena of boiling and condensation in the channels of small dimensions are not known particularly well for the moment and very little research is done for the channels smaller than $1 \mathrm{~mm}$.

It is important to mention that in microchannel two-phase flow the flow tends to be laminar for given conditions (apart from two-phase flow in conventional size channels, where turbulent flow is predominant) and in transition in some cases $(100<\mathrm{Re}<4000)$. Another factor of importance is that the capillary forces become more important in microchannels, while the importance of channel orientation diminishes and gravity forces become weaker (Palm, 2001). Flow patterns observed in 
small channels also differ from those observed in macrochannels. Four mostly observed are isolated bubble, confined bubble, annular-slug flow regimes and partial dryout (Kew and Cornwell, 1997).

Nucleate boiling has been found to be dominating in the flow boiling in single microchannels, apart from the conventional cases, where convective mechanism dominates. Generally to distinguish between the boiling mechanisms, it is necessary to observe the dependence of the heat transfer coefficient (HTC) on the heat flux and/or mass flux and vapour quality. If the HTC shows strong dependence on the heat flux, it can be concluded that the nucleate boiling dominates, which is characteristic for the conditions of high heat fluxes and low vapour quality. Nucleate boiling occurs when the driving temperature difference between the wall and the fluid is high enough to generate bubbles. In this case HTC is independent on the mass flux and vapour quality. Otherwise, the independence on the heat flux and dependence on the mass flux indicates the presence of the convective mechanism of boiling, which happens at high mass fluxes and high qualities.

Some studies (Lazarek and Black, 1982) have shown the dependence of the HTC on the heat flux in the saturated and subcooled boiling. It was observed that in the single rectangular mini-channels (2,5 mm hydraulic diameter) at low wall superheats (below 2,75 K) the dependence of the HTC on the heat flux is much lower than at the higher wall superheats (Tran et al., 1996).

Pressure drop in single-phase flow usually decreases with increasing heat flux. When boiling occurs, the pressure drop starts increasing due to the increase in vapour quality and keeps increasing until the critical heat flux is reached. Generally, the pressure drop during flow boiling is influenced by many parameters and it was concluded by a number of studies that pressure drop increases with the decrease of the hydraulic diameter of the channel. Pressure fluctuations are reported to be more prominent in the multi-channel systems. Surface roughness is reported to increase both HTC and pressure drop in mini-and microchannels with the decrease in channel dimensions (Celata, 2004).

Void fraction (cross sectional area occupied by the vapour related to the total cross-sectional area of the channel) is an important parameter for modelling and defining two-phase flows. Not particularly much has been done for determination of the void fraction in the microchannels and modelling is performed using the conventional approaches, accounting different models for specific cases. Very few visualisation studies on small channels have been performed (Triplett et al., 1999), so the work in this field is only at its initial stage.

There are gaps in understanding the flow regimes in round and rectangular mini- and micro channels, especially the influence of the aspect ratio and tube diameter on the flow pattern transitions. The difference between the transitions between flow regimes in round and rectangular channels of small diameters is increasing with the decrease of the tube diameter (Coleman, Garimella, 1998), which influences the heat transfer and pressure drop. The capillary effects become more important in the rectangular channels. In the rectangular tubes the liquid is detained in the corners, which on the one side is enhancing the heat transfer giving more possibility for bubble generation near the corners; and, on the other side, the liquid film on the wall becomes locally thinner. This may result in easier partial dryout, deteriorating the heat transfer (Yang and Fujita, 2004). This trade-off depends on operating conditions and has to be studied more in the future.

\section{Experimental set-up}

The test system is built in order to investigate heat transfer and pressure drop in a single rectangular copper microchannel during flow boiling of refrigerant R134a (Figure 1). The main loop is 
constructed of the test section (evaporator), circulation pump, condenser, subcooler and the measurement equipment. Tap water is used both for heating the evaporator and for cooling the condenser, being pre-heated or pre-cooled according to the necessary working conditions. The test section represents a two-channel copper evaporator, as shown in Figure 2. After passing the test section, the working fluid enters the condenser, where it is condensed and subcooled. After the condenser the refrigerant passes through a coil placed in an ice bath. This is necessary in order to secure the liquid phase of the refrigerant before entering the pump. The refrigerant is circulated by an ISMATEC pump, which can control small flow rates (up to $100 \mathrm{ml} / \mathrm{min}$ ) with high precision. Before entering the evaporator the refrigerant is pre-heated by an electrical heater, making it possible to create desired entrance conditions.

The evaporator (test section) is manufactured of three copper plates, each $5 \mathrm{~mm}$ thick. In two of them 0,2x6x180 mm layers were removed and when soldered all three together, the two channels were formed on each side of the middle plate. The assembled heat exchanger is shown in Figure 2. The rectangular channels' hydraulic diameter is of $0,39 \mathrm{~mm}$ and the internal volume of a single channel is $216 \mathrm{~mm}^{3}$. Warm water flows on one side and refrigerant on the other side of the heat exchanger and as it is built of copper, good conduction allows the temperature to be distributed across the plates with a difference of only a 0,5-0,8 degrees between the two furthermost points at any cross section. This gives the possibility to consider the refrigerant channel to be heated almost equally from both sides.
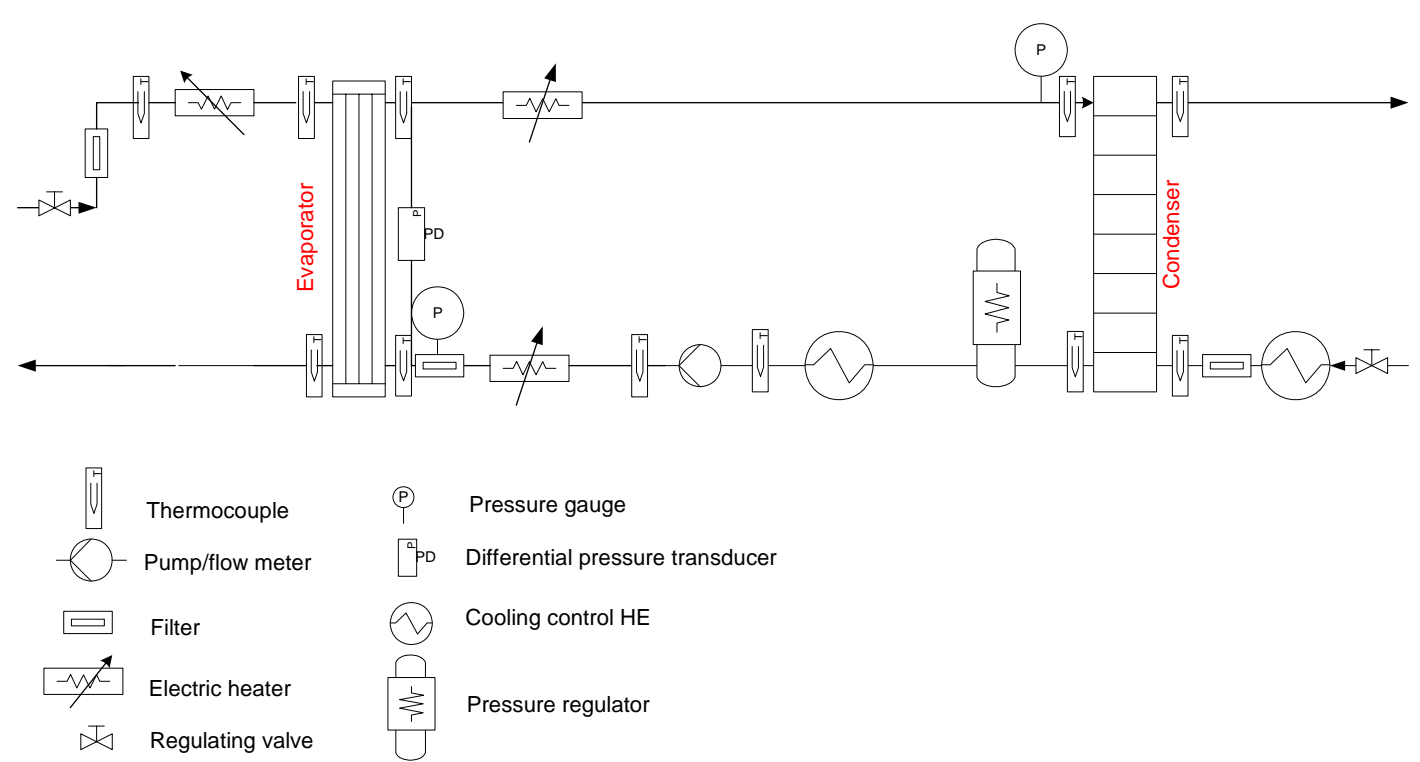

Figure 1. Test facility for investigation of flow boiling and pressure drop in single microchannel heat exchanger

The pressure in the system is controlled by the condenser water flow rate and by an electrical heater placed on a vessel (regulating the liquid level in the condenser). The pressure is measured by two absolute pressure transducers (Druck 20 bar, 0,08\% accuracy) placed at the evaporator inlet and the condenser inlet. The pressure drop in the evaporator is measured by a low differential pressure sensor (Druck 0-100 mbar, 0,25\% accuracy).

The fluid's temperatures are measured by 0,1 mm T-type thermocouples (Omega, $0,1^{0} \mathrm{C}$ error limit). The wall temperatures are measured by $\mathrm{T}$-type thermocouples $\left(0,1^{0} \mathrm{C}\right.$ error limit) placed on each 
external wall (both water and refrigerant side) at about $4 \mathrm{~cm}$ distances from each other. A total of 8 thermocouples were placed on the walls and other 4 at the fluids' inlets and outlets.
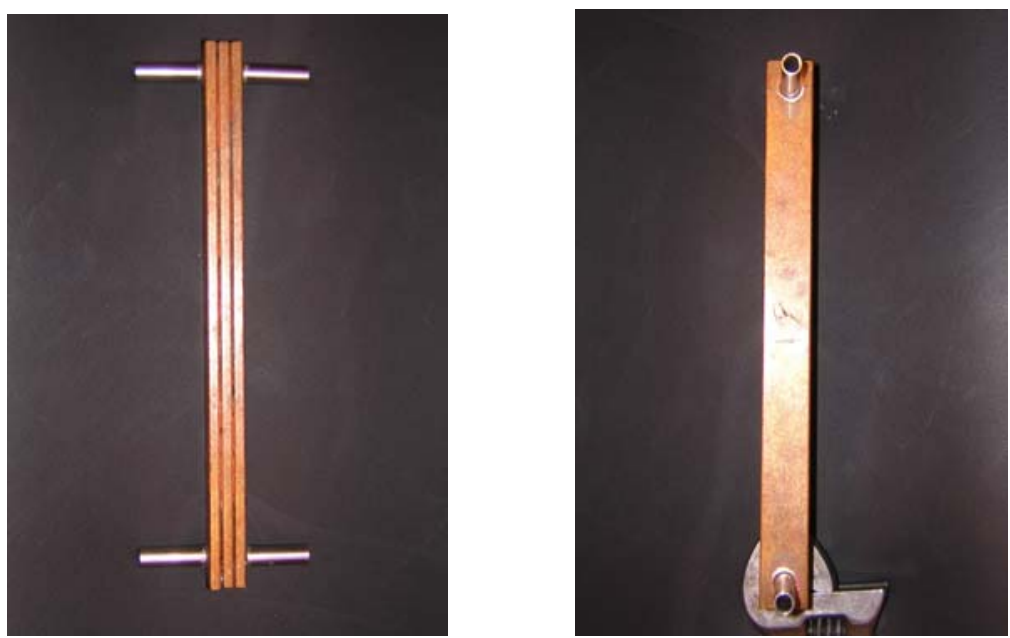

Figure 2. Single rectangular channel heat exchanger

The mass flow rate of refrigerant is set on the pump and additionally measured by a Micro-Oval mass flow meter (Oval M-III, accuracy within 1\%). The water mass flow rates of both the condenser and the evaporator sides were measured by a stopwatch and a graded vessel. Based on the given accuracies, error limits and uncertainty assumptions of the measured data, expected uncertainties of the calculated values were estimated using Engineering Equation Solver software (S.A.Klein, 1992-2005) with its built-in uncertainty propagation calculation method and are presented in the Table 1.

Table 1. Expected uncertainties of measured and calculated parameters

\begin{tabular}{|c|c|}
\hline Parameter & Uncertainty \\
\hline $\mathrm{A}, \mathrm{m}^{2}$ & $\pm 0,05^{*} \mathrm{~A}$ \\
\hline $\mathrm{P}, \mathrm{Pa}$ & $\pm 0,08 \%$ \\
\hline $\mathrm{T}_{\text {sat }}$ (according to the measured saturation pressure), ${ }^{0} \mathrm{C}$ & $\pm 0,16$ \\
\hline $\mathrm{T}_{\mathrm{w}},{ }^{0} \mathrm{C}$ & $\pm 0,1$ \\
\hline$\dot{\mathrm{q}}, \mathrm{W} / \mathrm{m}^{2}$ & $\pm 7 \%$ \\
\hline $\mathrm{h}, \mathrm{W} / \mathrm{m}^{2}-\mathrm{K}$ & $\pm 9 \%$ \\
\hline
\end{tabular}

\section{Data reduction and results}

The goal of this work was to experimentally study the heat transfer and pressure drop in boiling in a high aspect ratio rectangular microchannel and to compare the results with other studies using other geometries, as well as to apply existing correlations and see how well the heat transfer can be predicted for given conditions.

The data collected from the temperature, pressure and mass flow rate measurements were sufficient to determine the necessary heat transfer characteristics and pressure drop. However, more data is needed to be able to get a wider overview of the heat transfer and pressure drop and their dependence on the aspect ratio. 
Two sets of tests were performed - first keeping the inlet conditions (0,3-1 degrees subcooling) and the heat flux constant while changing mass flux, and second keeping the mass flux constant while changing heat flux. The tests were carried out at the working pressure of about 5 bar. The heat flux was in the range of $0,6-28 \mathrm{~kW} / \mathrm{m}^{2}$ and the mass flux was changed from 200 to $970 \mathrm{~kg} /\left(\mathrm{m}^{2} \mathrm{~s}\right)$ for each setting of the heat flux. The typical temperature distribution in the heat exchanger is presented below in the Figure 3. It can be seen that in axial direction temperature variation is of less than 2 degrees.

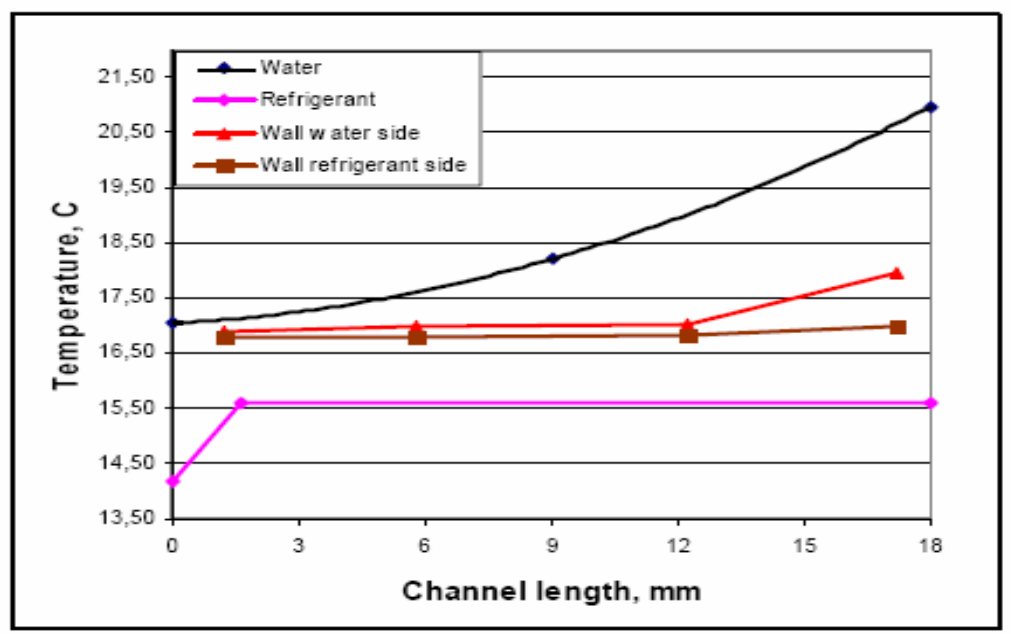

Figure 3. Typical temperature profiles taken for a $430 \mathrm{~kg} / \mathrm{m}^{2} \mathrm{~s}$ mass flux and a $4900 \mathrm{~W} / \mathrm{m}^{2}$ heat flux.

For the data evaluation, the heat transferred to the refrigerant is calculated from the water side heat balance:

$$
\dot{Q}=\dot{M} c_{p}\left(T_{\text {in }}-T_{\text {out }}\right)
$$

The average heat flux is obtained as the ratio of heat transferred to the refrigerant and heat transfer surface area. The water side heat transfer coefficient is changing little in axial direction due to the short thermal entrance length. The value of mean heat transfer coefficient on the refrigerant side was calculated using the difference between the mean wall temperature, calculated as the average of the four local wall temperatures and the saturation temperature of the refrigerant, as follows:

$$
h_{\text {mean }}=\frac{\dot{q}}{\left(T_{\text {mean }}-T_{\text {sat }}\right)},
$$

For the simplicity of calculation and based on the fact that the heat exchanger is well insulated and the heat losses to the environment are negligible, it was assumed that the temperatures inside the channel wall are equal to the measured outside wall temperatures.

The vapour quality of the fluid at the outlet is determined from the calculated outlet enthalpy and the point where boiling starts was calculated using the equation (3), assuming that $\mathrm{x}_{\text {local }}$ at that point equals zero:

$$
x_{\text {local }}=\frac{\dot{q} P\left(z-z_{0}\right)}{A_{c} \dot{m} \Delta H_{\mathrm{lg}}}
$$


The test results are presented in the Figures 4 to 6 .

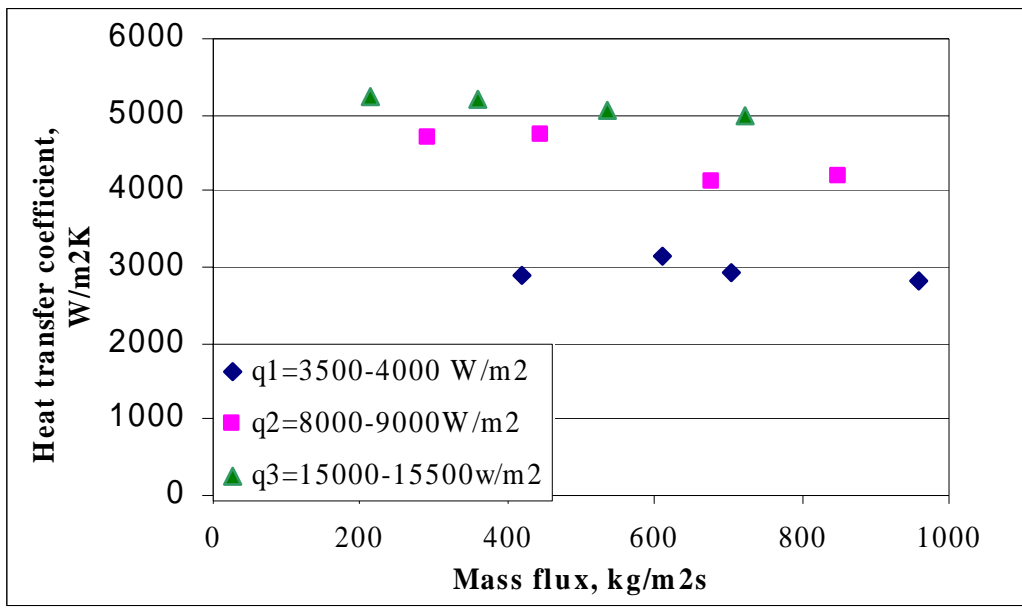

Figure 4. Variation of the HTC with the mass flux for different heat fluxes

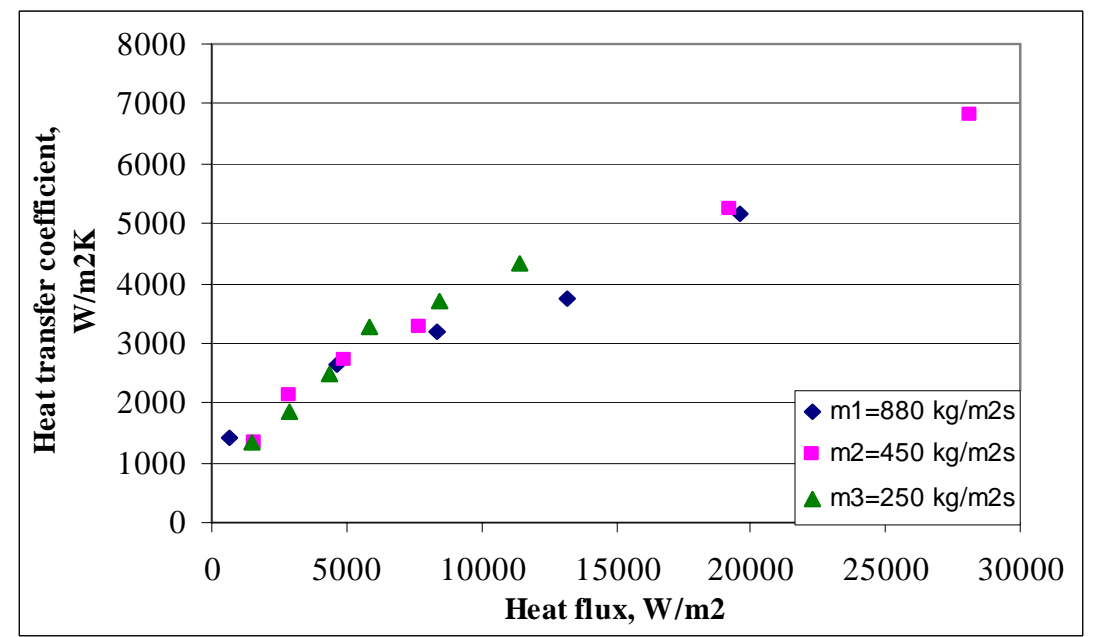

Figure 5. Variation of the mean HTC with the heat flux for different mass fluxes

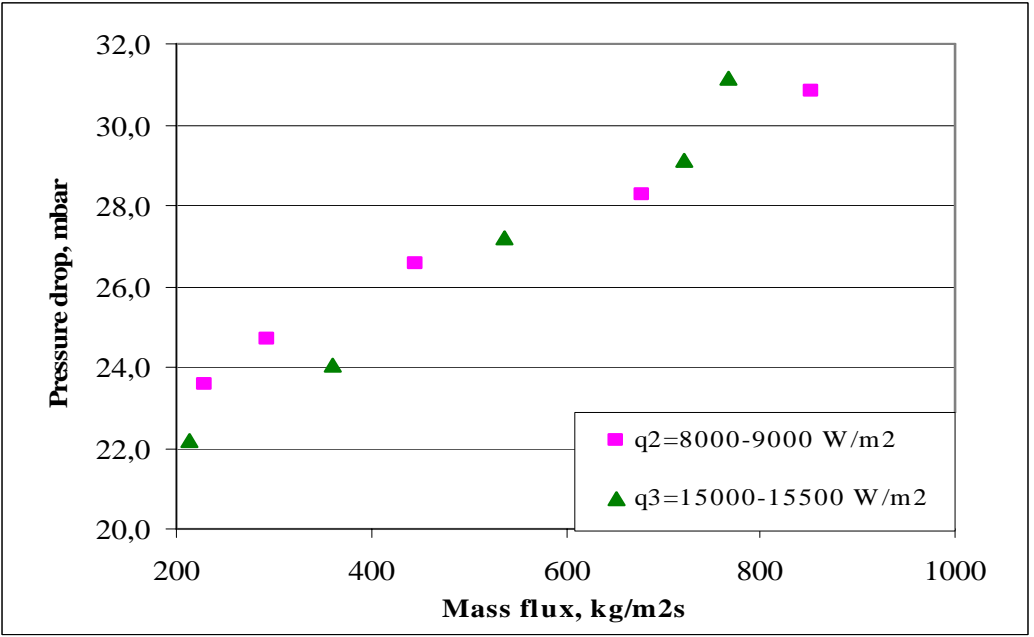

Figure 6. Variation of the pressure drop with the mass flux for different heat fluxes 
As can be seen from Figure 4, the heat transfer coefficient is not influenced by the change in mass flux, which indicates that boiling is not of the convective type. At the same time it can be seen that the dependence on the heat flux is quite obvious, which may be interpreted as indicating the dominance of nucleate boiling.

The preliminary results of the pressure drop measurements show an almost linear dependence on the mass flux. The dependence on the heat flux was not studied thoroughly and therefore is not reported here.

\section{Discussion}

The experimental values of heat transfer coefficients were compared with the predictions using the correlations developed by Lazarek and Black, 1982; Kew and Cornwell, 1997; Cooper (pool boiling, 1984, flow boiling, 1989) and Tran et al, 1996. Lazarek and Black proposed a correlation developed from the collected data for local saturated boiling heat transfer coefficient measurements using a least squares data fitting algorithm. They proposed the following expression for the Nusselt number:

$$
N u=30 \mathrm{Re}^{0,857} \mathrm{Bo}^{0,714}
$$

The correlation was developed for the $1,3 \mathrm{~mm}$ tube; heat fluxes of 14 to $380 \mathrm{~kW} / \mathrm{m}^{2}$; mass fluxes of 125 to $750 \mathrm{~kg} /\left(\mathrm{m}^{2} \mathrm{~s}\right)$; Reynolds numbers between 860 and 5500. The modified Lazarek and Black's correlation was suggested to observe the influence of the quality on the heat transfer coefficient and was found to work well for larger channels:

$$
N u=30 \operatorname{Re}^{0,857} B o^{0,714}(1-x)^{-0,143}
$$

For the present calculations, $\mathrm{x}_{\text {out }}$ value was taken as the outlet qualities were quite low and taking the mean value would not influence much the results.

Cooper has developed a correlation for pool boiling (Cooper, 1984, equation (6)) and modified it later on (Cooper, 1989, equation (7)) for vertical flow boiling at low quality. He recommended it to be used to give a trend until further correlations will be available for more precise calculations.

$$
\begin{aligned}
& h=55 p_{r}^{0,12}\left(-\log _{10} p_{r}\right)^{-0,55} \bar{M}^{-0,5} \dot{q}^{0,67} \\
& h=35 p_{r}^{0,12}\left(-\log _{10} p_{r}\right)^{-0,55} \bar{M}^{-0,5} \dot{q}^{0,67}
\end{aligned}
$$

Tran et al, 1996, have based their correlation on the tests for the circular ( $\mathrm{d}=2,46$ and 2,92 $\mathrm{mm}$ ) and rectangular channels $\left(\mathrm{d}_{\mathrm{h}}=2,4 \mathrm{~mm}\right)$ with $\mathrm{R} 12$ and R113. Mass fluxes varied between 44 and 832 $\mathrm{kg} /\left(\mathrm{m}^{2} \mathrm{~s}\right)$ and heat fluxes from 7,5 to $129 \mathrm{~kW} / \mathrm{m}^{2}$. Their correlation expresses the heat transfer coefficient as follows (in $\mathrm{kW} / \mathrm{m}^{2} \mathrm{~K}$ ):

$$
h=840\left(B o W e_{l}\right)^{0,3}\left(\frac{\rho_{l}}{\rho_{g}}\right)^{-0,4}
$$

The results of the experiments compared to the predicted values of heat transfer coefficients are presented in the Figures 8 to 12, where the lines show 30\% deviation. As can be seen from the figures, the values are predicted within 5 to $35 \%$ by both Lazarek \& Black and modified Lazarek \& Black's correlations. 


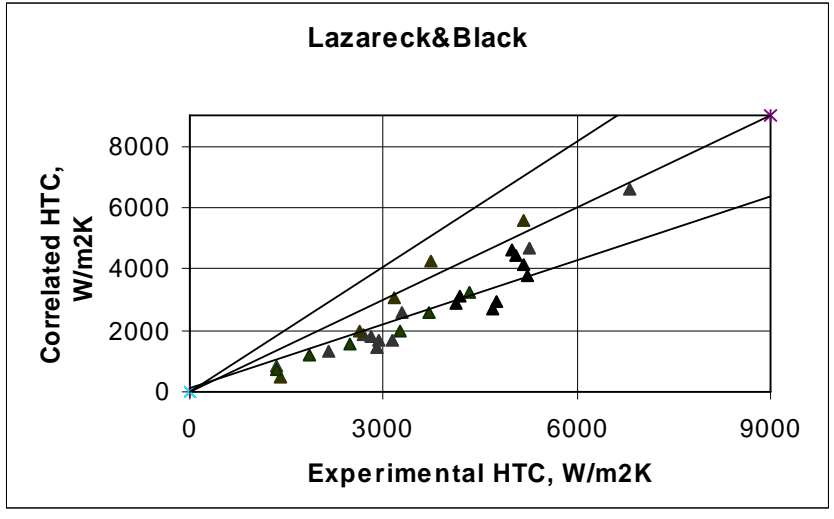

Figure 7. Comparison of the experimental mean heat transfer coefficient values with the values obtained from Lazareck\&Black correlation.

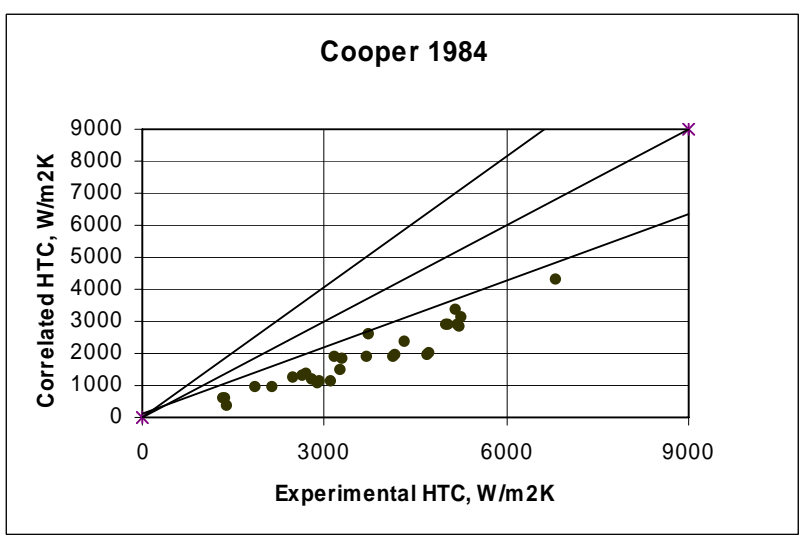

Figure 9. Comparison of the experimental mean heat transfer coefficient values with the values obtained from Cooper 1984 correlation.

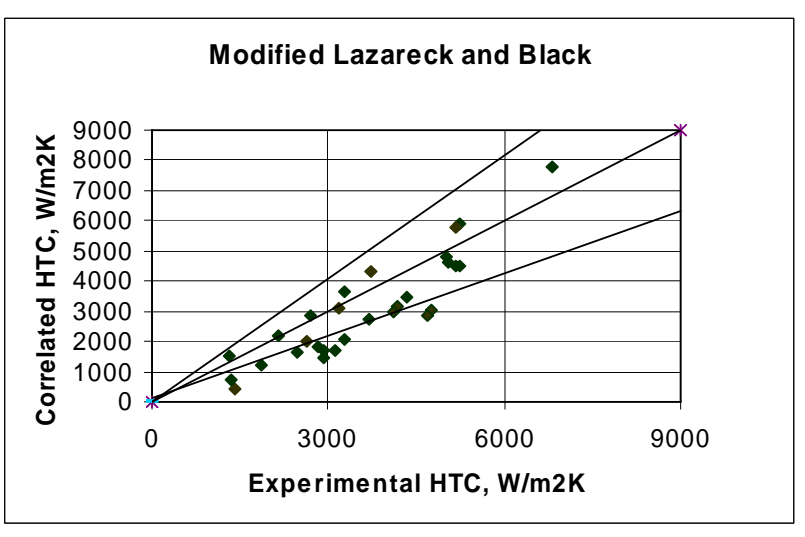

Figure 8. Comparison of the experimental mean heat transfer coefficient values with the values obtained from Modified Lazareck and Black correlation.

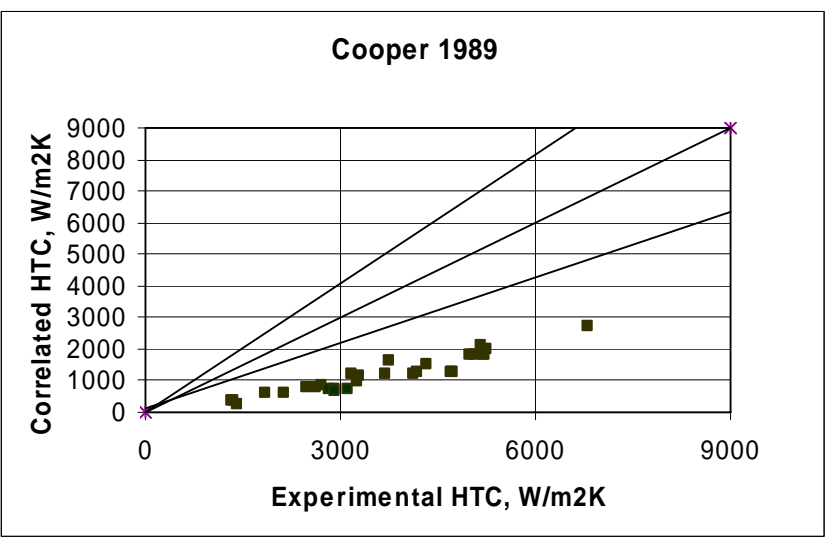

Figure 10. Comparison of the experimental mean heat transfer coefficient values with the values obtained from Cooper 1989 correlation.

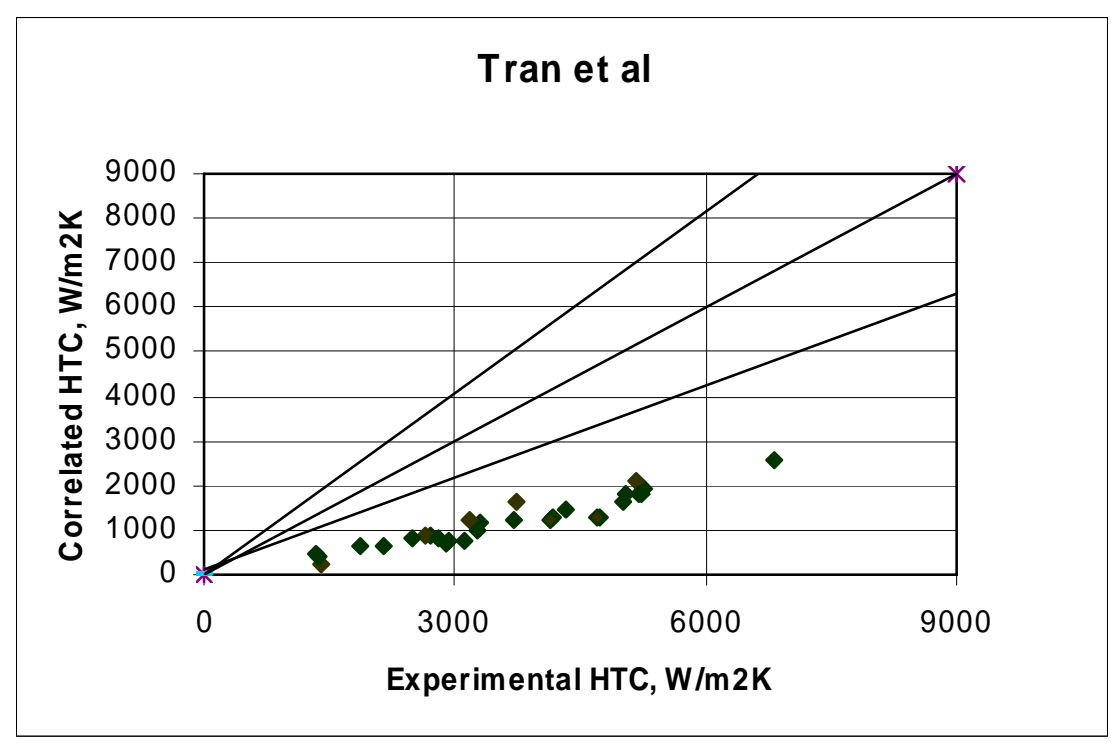

Figure 11. Comparison of the experimental mean heat transfer coefficient values with the values obtained from Tran et al.’s correlation 
Cooper's 1984 correlation underpredicts the values by more than 40\%, while Cooper 1989, as well as Tran et al's correlations give around $60 \%$ disagreement with experimental values.

\section{Conclusions}

Boiling heat transfer and pressure drop measurements were made in a high aspect ratio rectangular microchannel heat exchanger with R134a. The heat transfer coefficients were found to be highly dependent on the heat flux but more or less independent of mass flux within the applied range of mass and heat fluxes. This indicates that nucleate boiling, or a related process, is governing the heat transfer. Analysing the collected data it can be concluded that for the rectangular microchannel with the aspect ratio 1:30 and the hydraulic diameter $0,39 \mathrm{~mm}$ the results agree qualitatively with the data reported by other authors for circular and rectangular channels. Comparing the results against several existing heat transfer correlations, the best agreement was reached with the correlations proposed by Lazareck and Black - original and modified for taking into account the quality change. Cooper's 1984 pool boiling correlation shows the correct dependence on heat flux but underestimates the experimental data by about 40\%, while Cooper's 1989 flow boiling correlation ad Tran et al's correlation underestimate the experimental results by about $60 \%$. Pressure drop results have shown that the pressure drop increases more or less linearly with the mass flux.

More general conclusions will be possible in the near future as more data is generated. Further work is going on in order to study a larger range of parameters, specifically concerning the influence of the aspect ratio. The influence of pressure level and of the channel hydraulic diameter on the heat transfer and pressure drop will also be studied.

\section{References}

Celata, G.P., 2004, Heat transfer and fluid flow in microchannels, New York, Wallingford (UK)

Coleman, J.W., Garimella, S., 1998, Characterisation of two-phase flow patterns in small diameter round and rectangular tubes, Int. J. Heat and Mass Transfer 42, 2869-2881

Cooper, M.G., 1984, Saturation nucleate pool boiling, a simple correlation, IChemE Symp. Series No 86, Vol 2, 785-793

Cooper, M.G., 1989, Flow boiling - the apparently nucleate regime, Int. J. Heat and Mass Transfer 32, 459-464

Kandlikar, S.G., 2002, Fundamental Issues related to flow boiling in minichannels and microchannels, Experimental Thermal and Fluid Science 26, 389-407

Kew, P. and Cornwell, K., 1997, Correlations for Prediction of Boiling Heat Transfer in Small Diameter Channels, Applied Thermal Engineering,_17, No 8-10, 705-715

Klein, S.A., 1992-2005, Engineering Equation Solver, Academic Commercial version software

Lazarek, G.M., Black, S.H., 1982, Evaporative heat transfer, pressure drop and critical heat flux in a small vertical tube with R-113, Int. J. Heat and mass transfer 25, No.7, 945-960 
Palm, B., 2001, Heat transfer in Microchannels , Microscale Thermophysical Engineering $\underline{5}$, No 3, 155-175

Tran, T.N., Wambsganss, M.W., France, D.M., 1996, Small circular- and rectangular channel boiling with two refrigerants. Int. J. Multiphase flow, 22, No.3, 485-498

Triplett, K.A., Ghaasiaan, S.M., Abdel-Khalik, S.I., LeMouel, A., 1999, Gas-liquid two-phase flow in microchannels Part II: Void Fraction and Pressure drop, Int. J. Multiphase flow 25, 395-410

Yang, Y., Fujita, Y., 2004 Flow boiling heat transfer and flow pattern in rectangular channel of mini-gap, $2^{\text {nd }}$ International Conference on Microchannels and Minichannels, Rochester, New York, USA 